\title{
Hot Workability of the as-Cast 21Cr Economical Duplex Stainless Steel Through Processing Map and Microstructural Studies Using Different Instability Criteria
}

\author{
Jing $\operatorname{Han}^{1} \cdot$ Jia-Peng $\operatorname{Sun}^{2} \cdot$ Ying $\operatorname{Han}^{3} \cdot$ Huan Liu $^{2}$
}

Received: 22 June 2017/Revised: 15 August 2017/Published online: 13 September 2017

(C) The Chinese Society for Metals and Springer-Verlag GmbH Germany 2017

\begin{abstract}
To develop a fundamental understanding of the flow behavior and optimal hot workability parameters of this material, the hot workability and deformation mechanisms of the as-cast 21Cr EDSS were studied using processing map technology combined with microstructure analysis and isothermal hot compression over the temperature range of $1000-1150{ }^{\circ} \mathrm{C}$ and strain rate range of $0.01-10 \mathrm{~s}^{-1}$. The processing maps and constitutive equation of peak stress were developed based on Prasad's and Murty's criteria. The results show that the processing maps exhibit a stable domain at $1000-1150{ }^{\circ} \mathrm{C}$ and $0.01-1 \mathrm{~s}^{-1}$. The instability domain is exhibited at high strain rates $\left(\geq 1 \mathrm{~s}^{-1}\right)$. This implies that Murty's criterion can predict the unstable domain with high reliability. The detailed deformation mechanisms are also studied by microstructure observation, showing that the flow localization and microcracking are responsible for the flow instability.
\end{abstract}

KEY WORDS: Duplex stainless steel; Constitutive relationship; Processing map; Hot deformation behavior

\section{Introduction}

Owing to their excellent combination of mechanical properties and corrosion resistance, duplex stainless steels (DSSs) have been widely used in chemical, petrochemical, nuclear, and energy industries as well as diverse other fields [1-3]. The good properties of DSSs mainly rely on

Available online at http://link.springer.com/journal/40195

$$
\begin{aligned}
& 凶 \text { Jing Han } \\
& \text { hanjing@cumt.edu.cn } \\
& 凶 \text { Jia-Peng Sun } \\
& \text { sun.jiap@gmail.com }
\end{aligned}
$$

1 School of Mechanical and Electrical Engineering, China University of Mining and Technology, Xuzhou 221116, China

2 College of Mechanics and Materials, Hohai University, Nanjing 210098, China

3 Key Laboratory of Advanced Structural Materials, Ministry of Education, Changchun University of Technology, Changchun 130012, China the two-phase microstructure comprising approximately equal contents of the austenite and ferrite [4]. It is known that element $\mathrm{Ni}$ has been used to be an austenite stabilizer in DSSs, but it is very expensive and rare. Therefore, nickel can be partially or fully replaced by manganese and nitrogen for the same effect. Recently, Outokumpu Stainless developed a kind of LDX 2101 lean DSS, which features higher yield strength, better pitting resistance, and lower cost than conventional AISI 304 austenitic steel $[5,6]$.

DSSs can be processed by different modes, such as casting, rolling, forging, and extrusion under hot temperatures. However, different thermal expansion coefficients and deformation behavior of constituent phase, austenite, or ferrite in the duplex structure [7] can easily cause defects in the microstructure and properties during hot deformation such as edge cracking, which inevitably increases the difficulty in deformation at elevated temperatures. It is known that the ferrite with high stacking fault energy (SFE) undergoes dynamic recovery (DRV) during hot deformation. By contrast, the austenite with low SFE undergoes only limited dynamic recovery and easily suffers dynamic 
recrystallization (DRX) when the dislocation density accumulates to a critical value [8-10]. Hence, it is necessary to understand the material flow behavior and optimal hot workability parameters for improving the integrated properties and production rate of DSSs.

The hot deformation characteristics and processing map for a wide range of metals and alloys such as magnesium, aluminum, titanium, and Ni-based superalloys as well as stainless steel have been documented well in the literature [11-22]. Unfortunately, limited work has focused on the hot workability and microstructure evolution of the as-cast $21 \mathrm{Cr}$ economical duplex stainless steel (21Cr EDSS), especially on flow localization or instability in hot deformation, which will provide guidance for avoiding deformation defects.

In this study, the hot workability and deformation mechanisms of the as-cast $21 \mathrm{Cr}$ EDSS were studied via processing map technology in combination with microstructure analysis. The flow localization or instability of hot deformation was identified from the processing map employing Prasad's and Murty's instability criteria. Based on these, the optimal domain of hot working for $21 \mathrm{Cr}$ EDSS was proposed.

\section{Experimental Method}

\subsection{Experimental Procedures}

The chemical composition of the as-cast $21 \mathrm{Cr}$ EDSS employed in this work is as follows (mass\%): $0.02 \mathrm{C}, 0.58$ $\mathrm{Si}, 4.65 \mathrm{Mn}, 0.027 \mathrm{P}, 0.0043 \mathrm{~S}, 21.03 \mathrm{Cr}, 1.26 \mathrm{Ni}, 0.02 \mathrm{Cu}$, $0.03 \mathrm{Mo}, 0.236 \mathrm{~N}$, and balance $\mathrm{Fe}$. The initial microstructure before hot deformation observed by scanning electron microscopy (SEM) is shown in Fig. 1. It is seen that the insular $\gamma$-austenite is distributed in the $\delta$ ferritic matrix. The specimens were cut from the as-cast

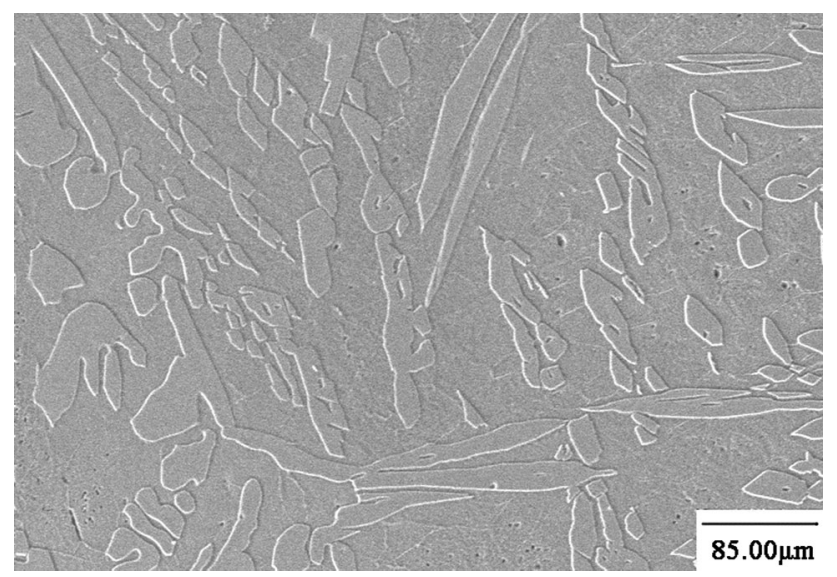

Fig. 1 SEM image of the as-cast 21Cr EDSS before hot deformation plates with $15 \mathrm{~mm}$ in height and $10 \mathrm{~mm}$ in diameter. Hot compression tests were performed in the temperature range of $1000-1150{ }^{\circ} \mathrm{C}$ and strain rate range of $0.01-10 \mathrm{~s}^{-1}$ on a Gleeble-1500D thermo-mechanical simulator. To minimize the friction between specimen and die, a tantalum foil with a thickness of $0.05 \mathrm{~mm}$ was inserted between them. All specimens were preheated to $1250{ }^{\circ} \mathrm{C}$, held for $4 \mathrm{~min}$ to achieve homogeneity, and then cooled to different deformation temperatures at a cooling rate of $5{ }^{\circ} \mathrm{C} / \mathrm{s}$ to simulate the practical industrial process. Before deformation, the specimens were held for $10 \mathrm{~s}$ to eliminate the thermal gradients. All specimens were deformed to a total true strain of 0.8 and water-quenched to room temperature. Hot deformed specimens were cut along the deformation axis, and the surfaces were prepared using optical microscopy observation. The specimens were etched with a solution of $10 \%$ oxalic acid in distilled water.

\subsection{Processing Map}

The processing maps and constitutive equation of peak stress were developed based on Prasad's and Murty's criteria. Processing maps based on DMM were established by Prasad and his coworkers [23] which are used to optimize the hot working parameters and control the microstructure and properties of products [24, 25]. In this model, the workpiece is considered as a dissipater of power, and the power $(P)$ can be separated into two parts:

$P=G+J=\int_{0}^{\dot{\varepsilon}} \sigma \mathrm{d} \dot{\varepsilon}+\int_{0}^{\sigma} \dot{\varepsilon} \mathrm{d} \sigma$,

where $G$ is the power dissipation by plastic deformation, $J$ is the power dissipation by microstructure change, $\sigma$ is the flow stress (MPa), and $\dot{\varepsilon}$ is the strain rate $\left(\mathrm{s}^{-1}\right)$. The power dissipation efficiency $(\eta)$ indicates how the workpiece dissipates energy efficiently by microstructural changes and is given through the following equation [26]:

$\eta=\frac{J}{J_{\max }}=\frac{2 m}{m+1}$,

where $J_{\max }$ represents the maximum $J$ when an ideal plastic flow is achieved and $m$ is the strain rate sensitivity which is assumed to be a constant.

The extremum principles of irreversible thermodynamics as applied to continuum mechanics of large plastic flow are employed to define the criterion for the flow instability [1], as follows:

$\xi_{1}(\dot{\varepsilon})=\frac{\partial \log [m /(m+1)]}{\partial \log \dot{\varepsilon}}+m \leq 0$.

However, the strain rate sensitivity $m$ is a function of strain rate and temperature, and its value varies at different deformation conditions, implying that Eq. (2) is inaccurate. 
To solve this issue, Murty and Rao [27, 28] proposed a modified and stricter plastic instability criterion in which $m$ is variable. The modified expression of $\eta$ is as follows:

$\eta=\frac{J}{J_{\max }}=2\left(1-\int_{0}^{\dot{\varepsilon}} \sigma \mathrm{d} \dot{\varepsilon}\right)$.

As everyone knows, the flow instability in materials occurs at $\mathrm{d} D / \mathrm{d} \dot{\varepsilon}<D / \dot{\varepsilon}$, where $D$ is a dissipative function at a particular temperature. Murty et al. [27, 28] pointed out that $D$ is equivalent to $J$ co-content. Thus, the following inequality can be obtained:

$\eta>2 m$.

Moreover, all the power is dissipated by plastic deformation for the complete adiabatic shear [29], which means $J=0$ and $\eta=0$. Therefore, a combined condition for the instability is established by:

$\eta>2 m$ or $\eta \leq 0$.

This instability criterion is valid for any type of constitutive relation, but it is difficult to perform the calculation of integration. In this study, Prasad's and Murty's criteria are used to estimate the flow instabilities of the as-cast $21 \mathrm{Cr}$ EDSS comparatively.

\section{Results and Discussion}

\subsection{Flow Stress}

Figure 2a shows the true stress-true strain curves of the ascast $21 \mathrm{Cr}$ EDSS at a strain rate of $0.01 \mathrm{~s}^{-1}$ and various deformation temperatures ranging from 1000 to $1150{ }^{\circ} \mathrm{C}$. The flow stress level clearly decreases with increasing deformation temperature at the same strain rate. Each flow curve exhibits a peak stress at relatively low strain $(\leq 0.02)$ followed by a gradual decrease in the flow stress to a steady state. The continuous stress softening after stress peak indicates that DRX process apparently dominates the microstructural changes during hot deformation. Figure $2 b$ shows the true stress-true strain curves at a temperature of $1150{ }^{\circ} \mathrm{C}$ and various strain rates ranging from 0.01 to $10 \mathrm{~s}^{-1}$. The flow stress level increases with increasing strain rate at the same deformation temperature. The DRX characterization can be found at strain rates below $1 \mathrm{~s}^{-1}$. However, there is no distinct stress drop at the strain rate of $1 \mathrm{~s}^{-1}$ owing to the balance of work hardening (WH) and dynamic softening, indicating that DRV becomes the main softening mechanism. It is interesting to note that the flow stress decreases after the first peak stress is observed within a true strain of approximately 0.1 followed by work hardening again in the true strain range of $0.1-0.2$ at a high strain rate of $10 \mathrm{~s}^{-1}$. The reason may lie in the

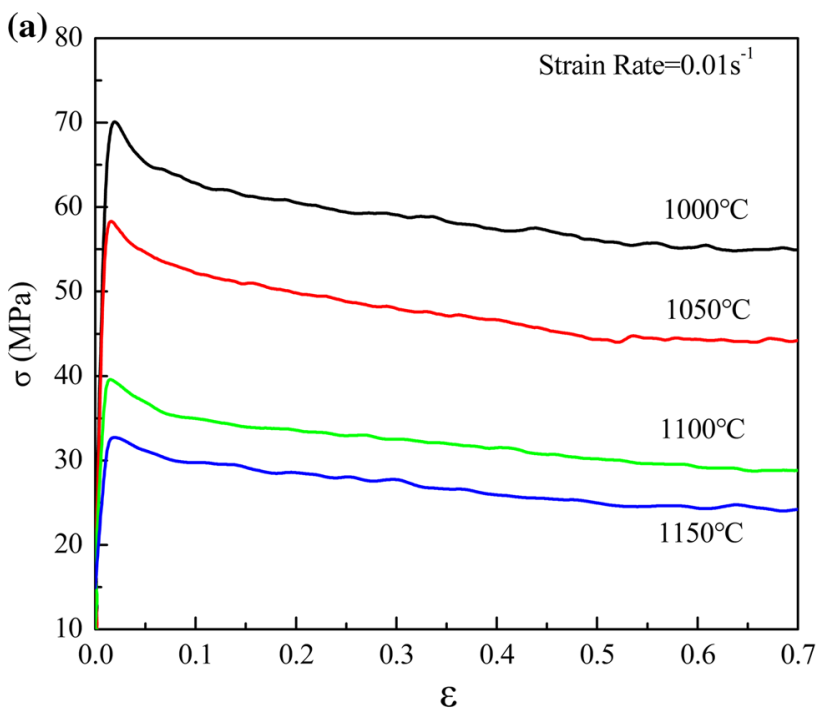

(b)

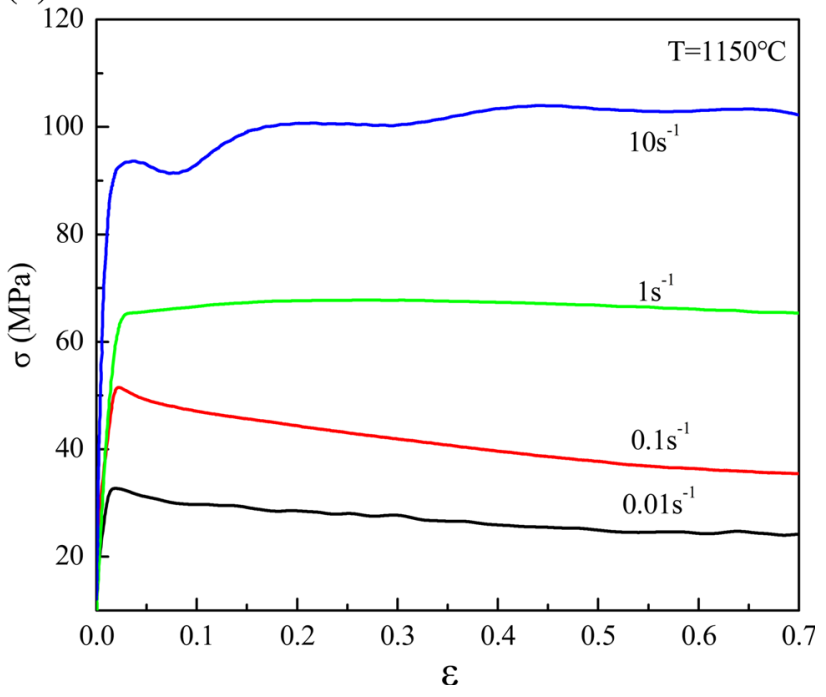

Fig. 2 True stress-true strain curves of the as-cast 21Cr EDSS under different deformation conditions: a $0.01 \mathrm{~s}^{-1}$, b $1150{ }^{\circ} \mathrm{C}$

uncoordinated deformation of the $\delta$-ferrite and austenite at the high strain rate. At early stages of deformation, the strain is mainly accommodated by the ferrite. With increasing strain, the load is transferred from the ferrite to the austenite. The hard austenite leads to the increment of stress to trigger further work hardening [30, 31].

\subsection{Kinetic Analysis}

\subsubsection{Peak Stress}

The peak stress $\left(\sigma_{\mathrm{p}}\right)$ can be determined from the true stress-true strain curves by calculating the work hardening rate $\theta(\theta=\partial \sigma / \partial \varepsilon)$ [32]. Figure 3 shows the plots of $\theta-\sigma$ at the strain rate of $0.01 \mathrm{~s}^{-1}$ with different temperatures, and at the temperature of $1150{ }^{\circ} \mathrm{C}$ with different strain 


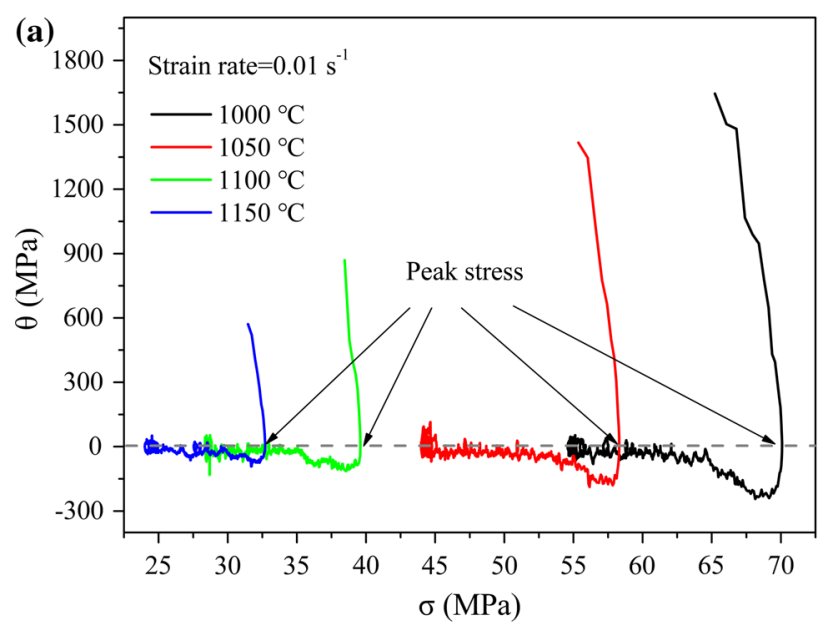

(b)

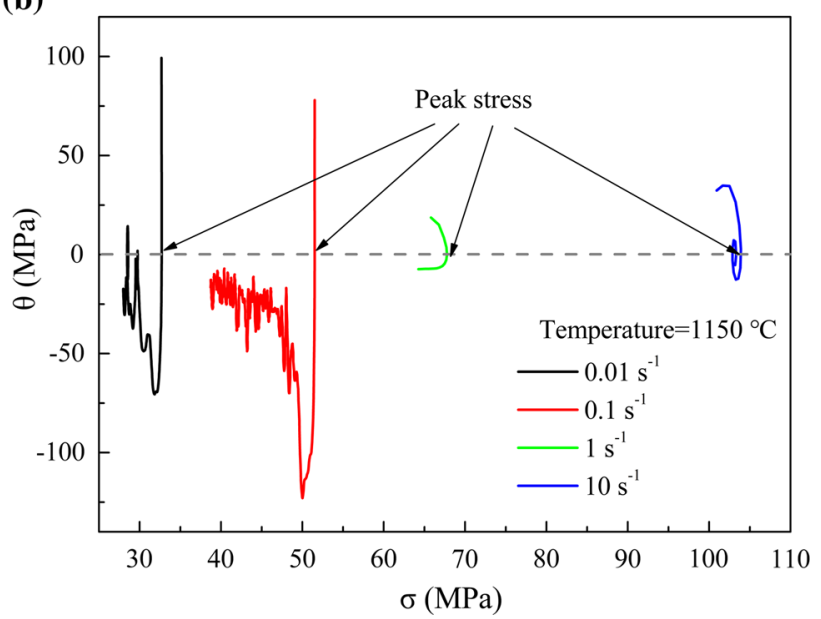

Fig. 3 Typical work hardening curves of the as-cast $21 \mathrm{Cr}$ EDSS under different deformation conditions: a $0.01 \mathrm{~s}^{-1}$, b $1150{ }^{\circ} \mathrm{C}$

rates, where the competition relationship between dynamic softening and work hardening can be distinguished. The positive $\theta$ means that the work hardening effect is stronger than the dynamic softening. By contrast, the dynamic softening will play a major role when the values of $\theta$ become negative. Therefore, the peak stress can be established at first occurrence of $\theta=0$ in the single peak flow stress curve [33]. While the second occurrence of $\theta=0$ indicates the balance of work hardening and dynamic softening has been achieved again. From this figure, it is clearly seen that peak stress decreases with increasing deformation temperature and decreasing strain rate, which means that the softening degree of material at high temperature and low strain rate is greater than that at other deformation conditions.

\subsubsection{Constitutive Analysis of Peak Stress}

In the process of hot deformation, the relationship among stress, temperature, and strain rate can be expressed by the power law using the Zener-Hollomon $(Z)$ parameter as follows [25]:

$Z=\dot{\varepsilon} \exp \left(\frac{Q}{R T}\right)$,

$\dot{\varepsilon}=A F(\sigma) \exp \left(-\frac{Q}{R T}\right)$,

$F(\sigma)=\left\{\begin{array}{lc}\sigma^{n_{1}} & \alpha \sigma<0.8 \\ \exp (\beta \sigma) & \alpha \sigma>1.2, \\ {[\sinh (\alpha \sigma)]^{n}} & \text { for all } \sigma\end{array}\right.$

where $\sigma$ is the flow stress (MPa), $\dot{\varepsilon}$ is the strain rate $\left(\mathrm{s}^{-1}\right)$, $Q$ is the activation energy of deformation $\left(\mathrm{J} \mathrm{mol}^{-1}\right), T$ is the absolute temperature $(\mathrm{K}), R$ is the gas constant $\left(8.314 \mathrm{~mol}^{-1} \mathrm{~K}^{-1}\right), n_{1}$ and $n$ are stress exponents $(n=1 /$ $m, m$ is the strain rate sensitivity), and $A$ and $\alpha$ are material constants, $\alpha=\beta / n_{1}$.

The peak flow stress $\left(\sigma_{\mathrm{p}}\right)$, strain rate $(\dot{\varepsilon})$, and deformation temperature $(T)$ were fitted to the stress function expressed by Eq. (9). Plots of $\ln \sigma-\ln \dot{\varepsilon}$ and $\sigma-\ln \dot{\varepsilon}$ are shown in Fig. $4 \mathrm{a}$ and b, respectively. It can be found that $n_{1}$ ranges from 6.105 to 7.246 and $\beta$ ranges from 0.0571 to $0.1052 \mathrm{MPa}^{-1}$. Hence, the average values of $n_{1}$ and $\beta$ can be calculated to be 6.637 and $0.0796 \mathrm{MPa}^{-1}$, respectively. Then, $\alpha=\beta / n_{1}=0.01199 \mathrm{MPa}^{-1}$, which is close to 0.012 $\mathrm{MP}^{-1}$ for high-chromium stainless steel [34]. Based on the plot of $\ln [\sinh (\alpha \sigma)]$ and $\ln \dot{\varepsilon}$ (Fig. 4c), the value of $n$ can be obtained by averaging the slopes of fitting lines. Here, the $n$ value is determined to be as 4.825 . The apparent activation energy $Q$, which is an important physical parameter associated with the workability of the materials, can be defined by

$Q=\left.R n \frac{\partial\{\ln [\sinh (\alpha \sigma)]\}}{\partial(1 / T)}\right|_{\dot{\varepsilon}, \varepsilon}$.

Figure 5a shows the plot of $\ln [\sinh (\alpha \sigma)]-10000 / T$ for various strain rates, where the average value of $Q$ can be calculated to be $482.617 \mathrm{~kJ} / \mathrm{mol}$. The hot deformation is a thermal activation process. The apparent activation energy reflects the activation barrier to proceed the deformation, indicating the ease or complexity of hot working [35]. Compared with other duplex stainless steels, for example 2304 DSS $(Q=263.4 \mathrm{~kJ} / \mathrm{mol})$ [1] and 2205 DSS ( $Q=405.8 \mathrm{~kJ} / \mathrm{mol}$ ) [36], the $Q$ value for $21 \mathrm{Cr}$ EDSS is much high, implying that the condition for starting DRX is quite rigorous.

The value of $A$ can be obtained by the plot of $\ln Z-\ln [\sinh (\alpha \sigma)]$, as shown in Fig. 5b. Through regression analysis, the relationship between $\ln Z$ and $\ln [\sinh (\alpha \sigma)]$ can be expressed as follows: 

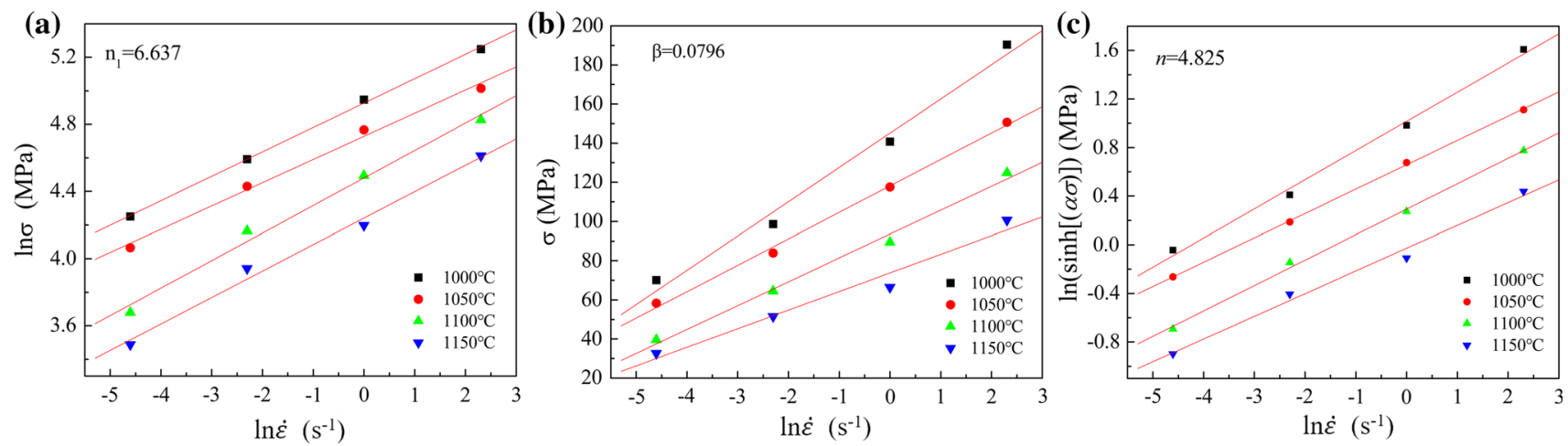

Fig. 4 Plots of a $\ln \sigma-\ln \dot{\varepsilon}, \mathbf{b} \sigma-\ln \dot{\varepsilon}$, and $\mathbf{c} \ln [\sinh (\alpha \sigma)]-\ln \dot{\varepsilon}$ at different temperatures

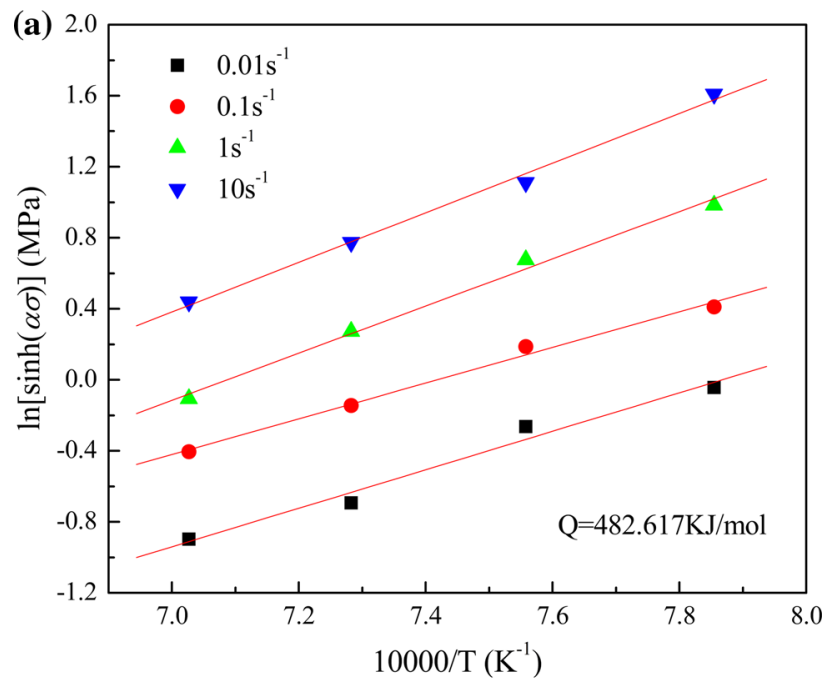

$$
\dot{\varepsilon}=5.352 \times 10^{17}[\sinh (0.01199 \sigma)]^{4.825} \exp \left(\frac{-482617}{R T}\right)
$$

\subsection{Hot Processing Map}

Based on DMM and two different instability criteria, processing maps comprising superimposition of a power dissipation map and instability map, which indicate stable and unstable domains during plastic processing, were developed, respectively.

Figure 6 shows the processing maps of the as-cast $21 \mathrm{Cr}$ EDSS at strains of 0.3 and 0.7 by Prasad's criterion and Murty's criterion. The contour numbers represent the power dissipation efficiency $(\eta)$, and the shaded domain with different tonalities of gray corresponds to flow instability occurring at different instability criteria. The darker

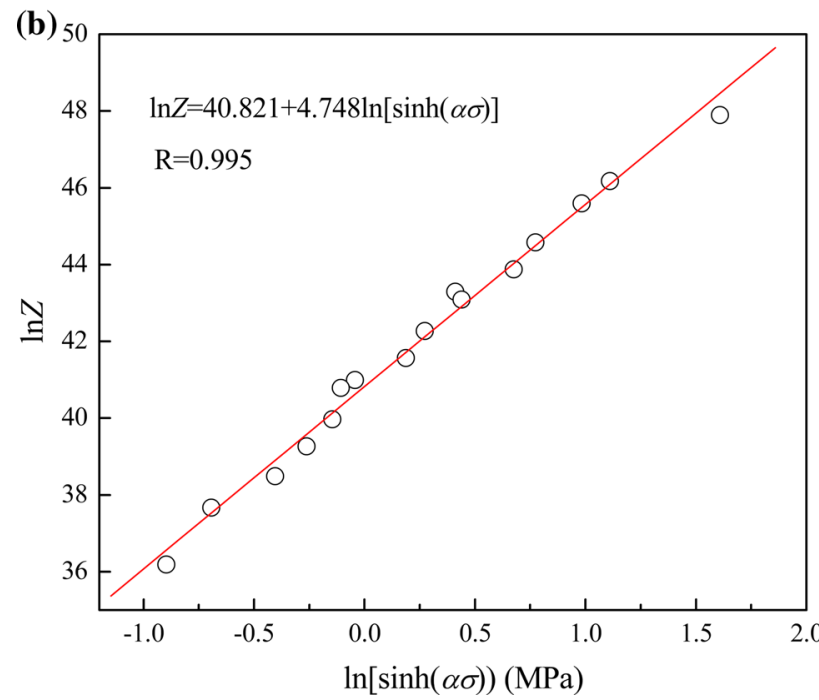

Fig. 5 Plots of $\mathbf{a} \ln [\sinh (\alpha \sigma)]-10000 / T$ and $\mathbf{b} \ln Z-\ln [\sinh (\alpha \sigma)]$ at different strain rates of peak stress

$\ln Z=40.8214+4.748 \ln [\sinh (\alpha \sigma)]$.

Thus, the constitutive equation for the as-cast $21 \mathrm{Cr}$ EDSS can be presented as: gray indicates the instability regime of Murty's criterion. The high power dissipation efficiency indicates that the material dissipates more energy for the microstructural changes, and this is the optimal processing condition for hot deformation [37].

It is clear that the evolution of power dissipation efficiency is complicated over the entire range of the temperatures and strain rates. At strain rates below $0.1 \mathrm{~s}^{-1}$, the power dissipation efficiency increases with increasing strain rates and temperatures. At strain rates between 0.1 and $1 \mathrm{~s}^{-1}$, the contour lines present shrunk loops with increasing strain rates and temperature, and the peak value is found in the temperature range of 1100 to $1150{ }^{\circ} \mathrm{C}$. However, at strain rates exceeding $1 \mathrm{~s}^{-1}$, the power dissipation efficiency decreases with increasing strain rates. Thus, Fig. $6 \mathrm{~b}$ can exhibit one domain (D2) at $1075-1150{ }^{\circ} \mathrm{C}$ and $0.08-0.7 \mathrm{~s}^{-1}$ with peak power dissipation efficiency of $48 \%$, which is higher than that in Fig. 6 a and is often associated with dynamic recrystallization [38]. Moreover, the peak power dissipation efficiency is moving to a strain rate range of $0.1-1 \mathrm{~s}^{-1}$ and increases with increasing strain (in Fig. 7). The power dissipation 

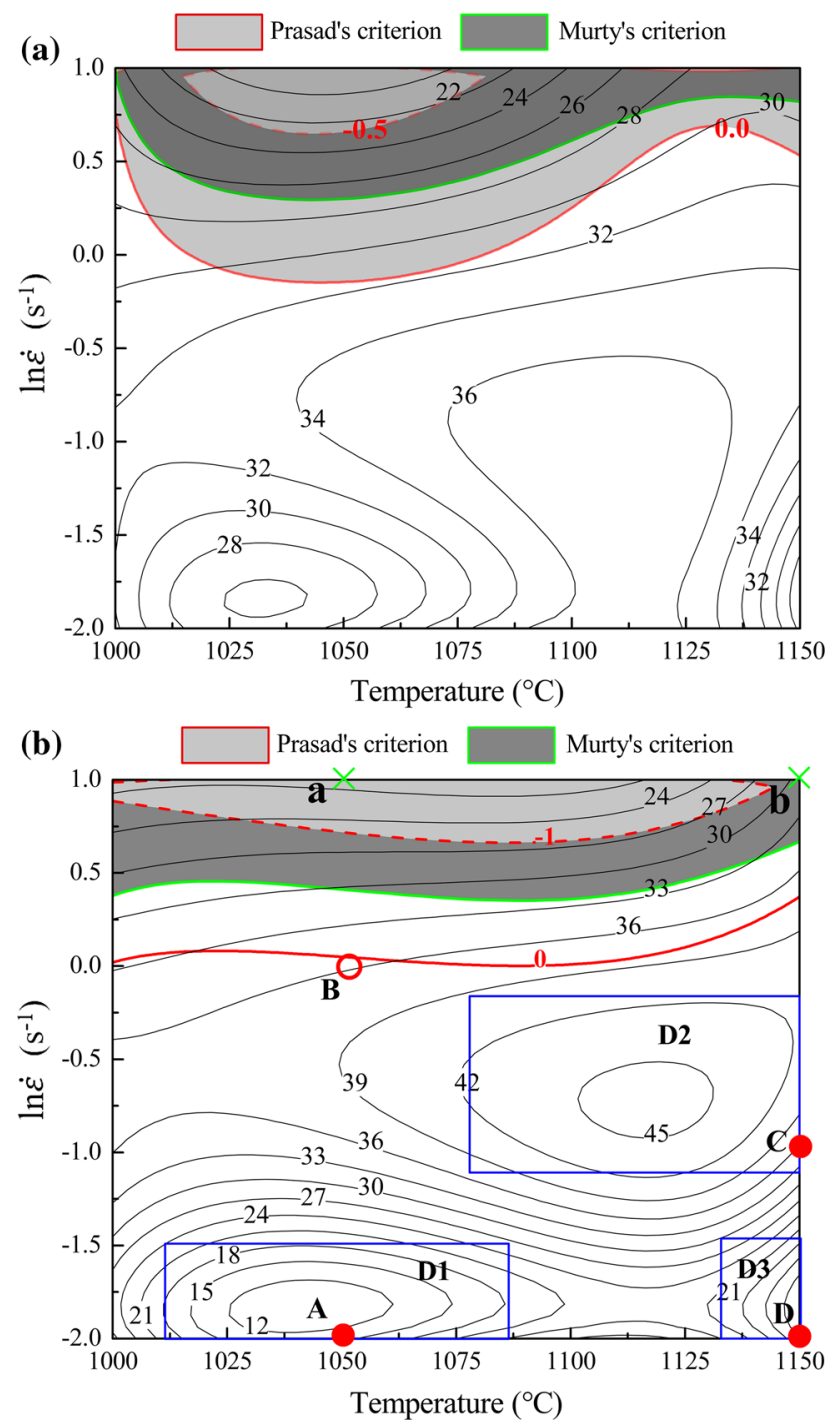

Fig. 6 Processing maps of the as-cast 21Cr EDSS at strains of 0.3 and 0.7 based on Prasad's and Murty's criteria: $\mathbf{a} \varepsilon=0.3, \mathbf{b} \varepsilon=0.7$

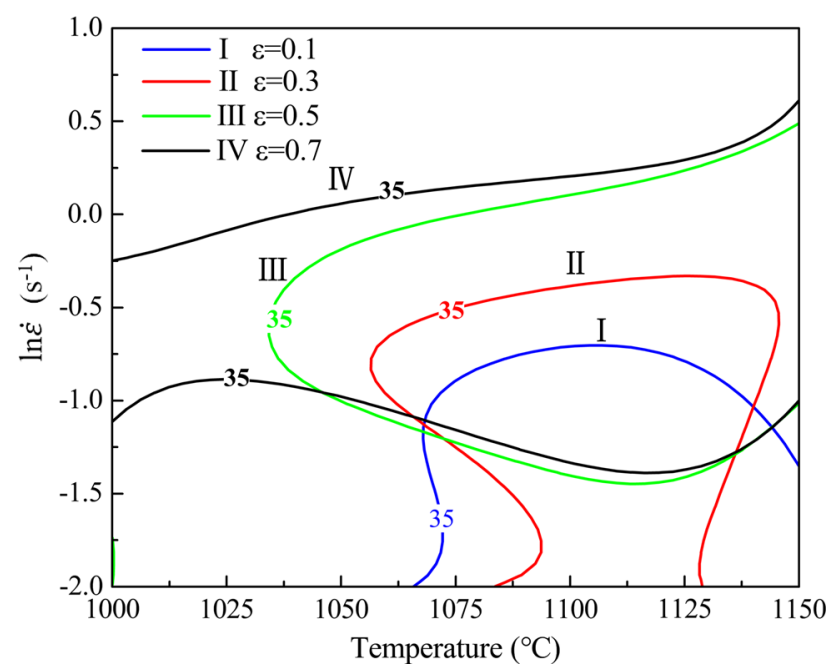

Fig. 7 Distribution of peak power dissipation efficiency with strain efficiencies in domains D1 $\left(1010-1085^{\circ} \mathrm{C}\right.$, $\left.0.01-0.032 \mathrm{~s}^{-1}\right)$ and D3 (1132-1150 $\left.{ }^{\circ} \mathrm{C}, 0.01-0.034 \mathrm{~s}^{-1}\right)$ are lower than those of the corresponding region in Fig. 6 a.

As seen in Fig. 6, the instability domain in light gray with a red solid line is the instability regime of Prasad's criterion, and the darker gray domain with a green solid line is the instability regime of Murty's criterion, which is unsuited for hot deformation. It is found that the instability domain developed by Prasad's criterion is slightly wider than that of Murty's criterion. Both criteria for the instability regimes in the entire temperature range and high strain rate range of $1-10 \mathrm{~s}^{-1}$ slightly vary with increasing strain. To avoid mathematical error in the boundary region when calculating $\xi$ values in Eq. (3), Chiba et al. [39] proposed that the instability domain could be divided into two parts depending on the value of $\xi$ : metastable domain $(-1<\xi<0)$ and completely unstable domain $(\xi<-1)$. Thus, the light gray region between the red solid line and red dash line is the metastable domain, in which stable and unstable characteristics may be observed. The light gray region with the red dash line is the completely unstable domain, in which flow instability is certain to emerge.

\subsection{Microstructural Analysis}

\subsubsection{Stability Domain}

Figure 8 exhibits typical microstructures of the deformed specimens from the regions of the processing map. These microstructures are in good agreement with the results from the processing map. The fraction of the ferrite increases with increasing temperature owing to the occurrence of a $\gamma \rightarrow \delta$ phase transformation. Figure 8a shows the microstructure deformed at $1050{ }^{\circ} \mathrm{C}$ and $0.01 \mathrm{~s}^{-1}$, which is marked point $\mathrm{A}$ in the map (D1) with the lowest power dissipation efficiency in the stability domain. As indicated by arrows, sharper boundaries in both the ferrite and austenite implied that dynamic recovery is the main softening mechanism, and limited DRV accounts for low power dissipation efficiency. This is owing to the coexistence of the ferrite and austenite at high temperatures in which the ferrite is soft and the austenite is rigid. The load is transferred from the ferrite to austenite, leading to the ferrite being deformed before austenite [40]. At high temperatures and low strain rates, the load transferring to the austenite is delayed and only ferrite undergoes DRV. Meanwhile, the DRV or DRX occurring in the ferrite retards or even inhibits the occurrence of DRX in the austenite [8, 40]. Figure $8 \mathrm{~b}$ shows the microstructure of point B (Fig. $6 \mathrm{~b}, 1050{ }^{\circ} \mathrm{C}, 1 \mathrm{~s}^{-1}$ ) on the edge of the flow instability region for Prasad's criterion. Obviously, many more equiaxed grains with a finer average grain size of the ferrite and partial austenite grains elongated along the 

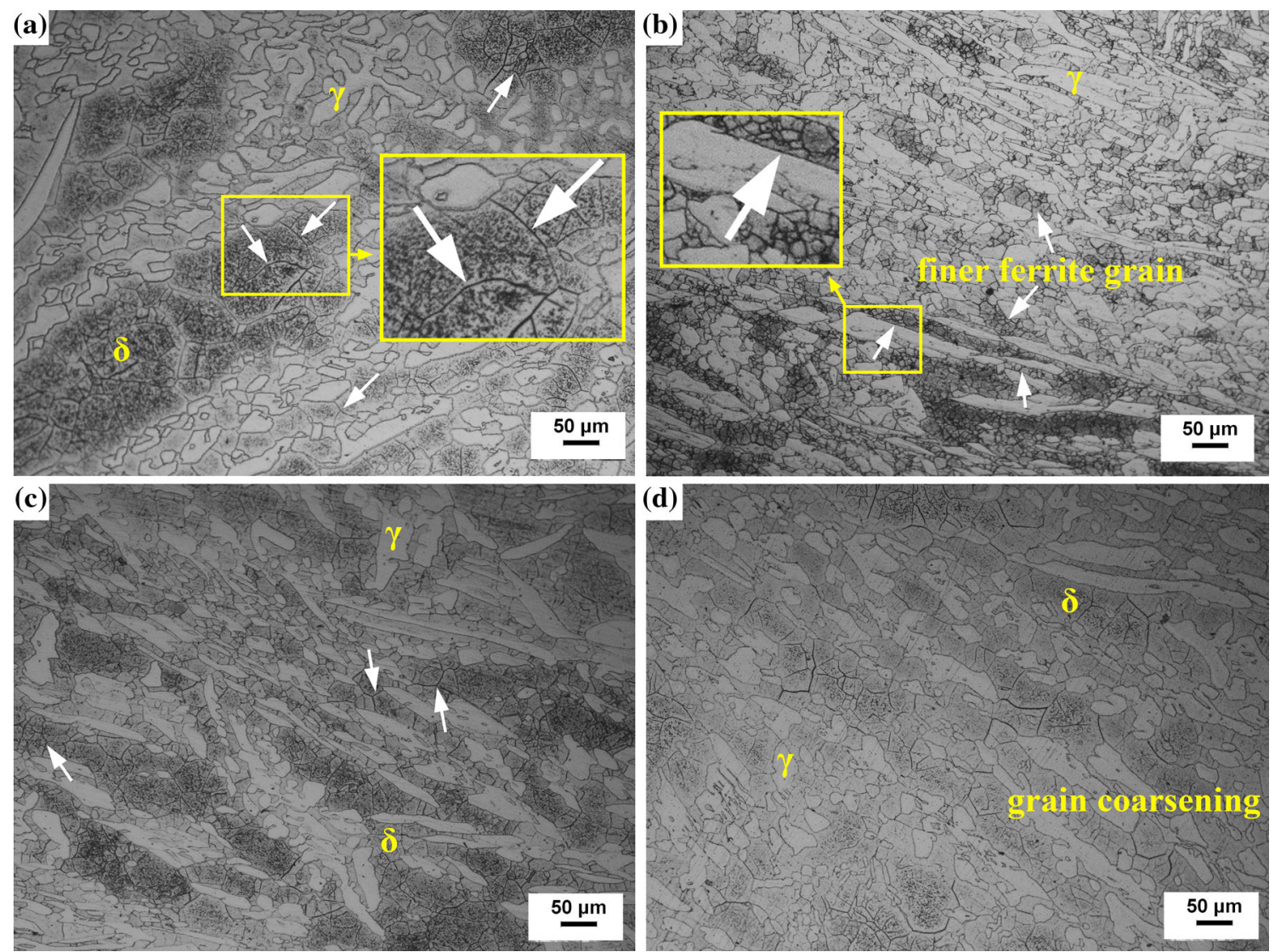

Fig. 8 Optical deformed microstructures under different conditions: a $1050{ }^{\circ} \mathrm{C}, 0.01 \mathrm{~s}^{-1}$, b $1050{ }^{\circ} \mathrm{C}, 1 \mathrm{~s}^{-1}, \mathrm{c}^{1} 150{ }^{\circ} \mathrm{C}, 0.1 \mathrm{~s}^{-1}, \mathbf{d ~} 1150{ }^{\circ} \mathrm{C}$, $0.01 \mathrm{~s}^{-1}$. The inserts show the magnification of the positions highlighted by the yellow rectangle box

vertical direction of the deformation are observed, illustrating that a higher strain rate can promote the occurrence of DRX in the ferrite, and no defects can be found in Fig. $8 \mathrm{~b}$ under the experimental condition. Figure 8c shows the microstructure marked point $\mathrm{C}$ at the deformation condition of $1150{ }^{\circ} \mathrm{C}$ and $0.1 \mathrm{~s}^{-1}$ corresponds to domain D2, which is the peak power dissipation efficiency of the processing map. It can be seen that full DRX ferrite grains are formed and finer spheroidizing austenite grains are observed, which is also the typical characterization of DRX [41]. A typical microstructure is obtained for the specimen at the deformation condition of $1150{ }^{\circ} \mathrm{C}$ and $0.01 \mathrm{~s}^{-1}$, which is marked point $\mathrm{D}$ in region $\mathrm{D} 3$ as shown in Fig. 8d; it can be seen that full dynamic recrystallization occurs, and the newly formed DRX grains coarsened remarkably.

\subsubsection{Instability Domain}

Figure 9 shows the deformed microstructures in the instability domain. It is observed that inhomogeneous deformation is the major unstable characteristic. Figure 9a shows the microstructure deformed at $1050{ }^{\circ} \mathrm{C}$ and $10 \mathrm{~s}^{-1}$, which is marked by the cross a in Fig. 6b. As seen in Fig. 9a, there is microcracking and flow localization during the present deformation condition. The microcracking may be related to the stress concentration. The flow localization is associated with the local temperature rise at high strain rates. This is because high strain rates cause adiabatic deformation heat owing to insufficient deforming time and low thermal conductivity of the material [42]. The microstructure of the specimen deformed at $1150{ }^{\circ} \mathrm{C}$ and $10 \mathrm{~s}^{-1}$ (marked as cross b) is shown in Fig. 9b, which is located in the metastable domain of Prasad's criterion and in which several microcracks can be observed. Figure 9c shows the transmission electron microscopy (TEM) image of $1150{ }^{\circ} \mathrm{C}$ and $10 \mathrm{~s}^{-1}$; the wedge cracks form at the interface of the ferrite and austenite. Meanwhile, an obvious occurrence of DRX in the ferrite can be observed, which may result in the enhanced values of power dissipation efficiency.

From the foregoing analyses of the processing map and the microstructures, it can be concluded that the optimal processing condition for this material with peak power dissipation efficiency of approximately $48 \%$ in the 

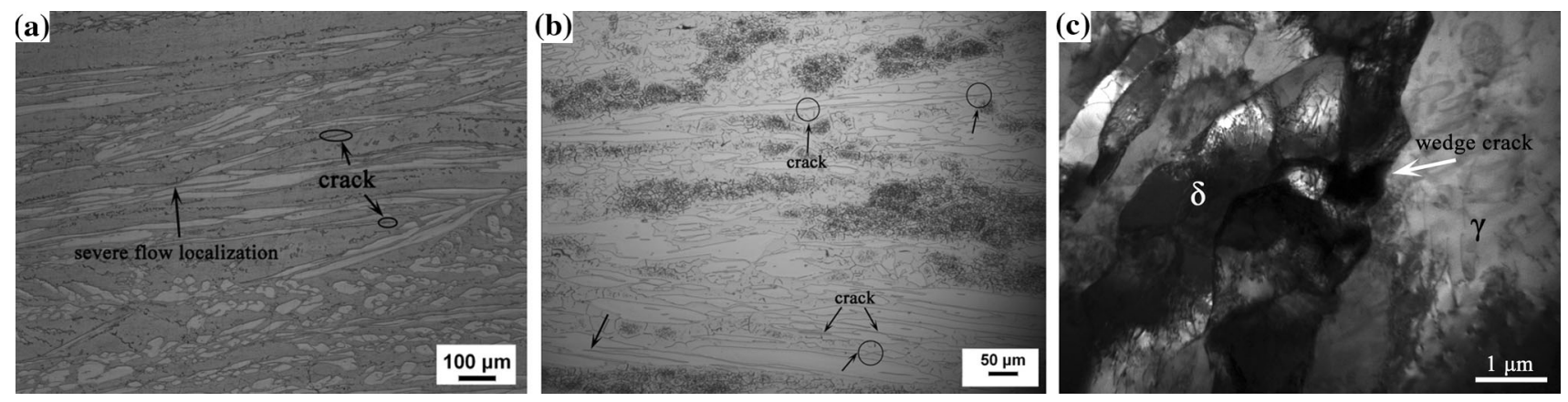

Fig. 9 Microstructure characteristics of the specimens deformed in the unstable domain: a $1050{ }^{\circ} \mathrm{C}, 10 \mathrm{~s}^{-1}, \mathbf{b ~} 1150{ }^{\circ} \mathrm{C}, 10 \mathrm{~s}^{-1}$, c TEM image of $1150{ }^{\circ} \mathrm{C}, 10 \mathrm{~s}^{-1}$

temperature range of $1075-1150{ }^{\circ} \mathrm{C}$ and strain rate range of $0.08-0.7 \mathrm{~s}^{-1}$ achieved full and uniform dynamic recrystallization.

\section{Conclusions}

The hot deformation workability of the as-cast 21Cr EDSS was studied by hot compression tests in the temperature range of $1000-1150{ }^{\circ} \mathrm{C}$ and strain rate range of $0.01-10 \mathrm{~s}^{-1}$. The conclusions are listed below.

1. The temperature and strain rate significantly influence the flow stress of the as-cast $21 \mathrm{Cr}$ EDSS. The flow stress increases with increasing strain rate and decreasing temperature. In addition, double work hardening is exhibited at the high strain rate of $10 \mathrm{~s}^{-1}$.

2. The hyperbolic sine function can be used to describe the relationship among peak stress, strain, and temperature. The stress parameter $n$ and deformation activation energy $Q$ are calculated to be 6.637 and $482.617 \mathrm{~kJ} / \mathrm{mol}$, respectively.

3. The processing maps of the as-cast $21 \mathrm{Cr}$ EDSS at strains of 0.3 and 0.7 were developed based on Prasad's and Murty's criteria. At lower strain rates and lower deformation temperatures, DRV is mainly the softening mechanism. The complete DRX of the ferrite and spheroidizing austenite occurs in the deformation temperature range of $1075-1150{ }^{\circ} \mathrm{C}$ and strain rate range of $0.08-0.7 \mathrm{~s}^{-1}$ with peak power dissipation efficiency of $48 \%$.

4. Murty's criterion has been used to predict the unstable domain for the as-cast $21 \mathrm{Cr}$ EDSS with high reliability. Flow instability occurs in the region of high strain rate $\left(\geq 1 \mathrm{~s}^{-1}\right)$. Flow localization and microcracking are responsible for this flow instability.

Acknowledgments The authors acknowledge the financial support received from the National Natural Science Foundation of China (Grant No. 51505479), the Jiangsu Natural Science Foundation of China (Grant No. BK20150184), and the Fundamental Research
Funds for the Central Universities (Grant No. 2014QNA36). We are also grateful to the use of computing resources at the Advanced Analysis and Computation Center of China University of Mining and Technology (CUMT).

\section{References}

[1] Y. Han, D.N. Zou, Z.Y. Chen, G.W. Fan, W. Zhang, Mater. Charact. 62, 198 (2011)

[2] C.M. Garzón, A.P. Tschiptschin, Mater. Sci. Eng. A 441, 230 (2006)

[3] V.S. Moura, L.D. Lima, J.M. Pardal, A.Y. Kina, R.R.A. Corte, S.S.M. Tavares, Mater. Charact. 59, 1127 (2008)

[4] R. Badji, M. Bouabdallah, B. Bacroix, C. Kahloun, B. Belkessa, H. Maza, Mater. Charact. 59, 447 (2008)

[5] W. Zhang, L. Jiang, J. Hu, H. Song, Mater. Charact. 60, 50 (2009)

[6] M. Liljas, P. Johansson, H.P. Liu, C.O A Olsson. Steel Res. Int. 79, 466 (2008)

[7] T. Siegmund, E. Werner, F.D. Fischer, Mech. Phys. Solids 43, 495 (1995)

[8] H. Farnoush, A. Momeni, K. Dehghani, J. Aghazadeh Mohandesi, H. Keshmiri, Mater. Des. 31, 220 (2010)

[9] A. Momeni, A. Shokuhfar, S.M. Abbasi, Mater. Sci. Technol. 23, 775 (2007)

[10] A. Momeni, K. Dehghani, H. Keshmiri, G.R. Ebrahimi, Mater. Sci. Eng. A 527, 1605 (2010)

[11] S. Anbuselvan, S. Ramanathan, Mater. Des. 31, 2319 (2010)

[12] G. Meng, B.L. Li, H.M. Li, H. Huang, Z.R. Nie, Mater. Sci. Eng. A 517, 132 (2009)

[13] N.K. Park, J.T. Yeom, Y.S. Na. J. Mater. Process. Technol. 130, 540 (2002)

[14] D.Y. Cai, L.Y. Xiong, W.C. Liu, G.D. Sun, M. Yao, Mater. Des. 30, 921 (2009)

[15] S.P. Tan, Z.H. Wang, S.C. Cheng, Z.D. Liu, J.C. Han, W.T. Fu, Mater. Mater. Sci. Eng. A 517, 312 (2009)

[16] Y. Yan, X.D. Peng, F.J. Ren, H.M. Wen, J.F. Su, W.D. Xie, J. Mater. Sci. Technol. 32, 1289 (2016)

[17] G. Wang, L. Xu, Y. Wang, Z. Zheng, Y.Y. Cui, R. Yang, J. Mater. Sci. Technol. 27, 893 (2011)

[18] S. Ramanathan, R. Karthikeyan, V. Deepak, G.Ganesan Kumar, J. Mater. Sci. Technol. 22, 611 (2006)

[19] F. Kang, J. Sun, G. Zhang, Z. Li, J. Mater. Sci. Technol. 25, 373 (2009)

[20] J.Q. Li, J. Liu, Z.S. Cui, Acta Metall. Sin. (Engl. Lett.) 28, 1364 (2015) 
[21] X.X. Yu, Y.R. Zhang, D.F. Yin, Z.M. Yu, S.F. Li, Acta Metall. Sin. (Engl. Lett.) 28, 817 (2015)

[22] Y. Zhang, H.L. Sun, A.A. Volinsky, B.H. Tian, Z. Chai, P. Liu, Y. Liu, Acta Metall. Sin. (Engl. Lett.) 29(5), 422 (2016)

[23] Y.V.R.K. Prasad, S. Sasidhara, ASM International, USA (1997)

[24] V.V. Balasubrahmanyam, Y.V.R.K. Prasad, Mater. Sci. Eng. A 336, 150 (2002)

[25] D.N. Zou, Y. Han, D.N. Yan, D. Wang, W. Zhang, G.W. Fan, Mater. Des. 32, 4443 (2011)

[26] Y.V.R.K. Prasad, H.L. Gegel, S.M. Doraivelu, J.C. Malas, J.T. Morgan, K.A. Lark, D.R. Barker. Metall. Mater. Trans. A 15, $1883(1984)$

[27] S.V.S.N. Murty, B.N. Rao, Mater. Sci. Eng., A 254, 76 (1998)

[28] S.V.S.N. Murty, B.N. Rao, J. Phys. D- Appl. Phys. 31, 3306 (1998)

[29] X. Li, S.Q. Lu, K.L. Wang, M.W. Fu, Z.X. Li, C.X. Cao, Rare Metal Mat. Eng. 37, 0577 (2008)

[30] J.A. Jinmenze, F. Carreno, O.A. Ruano, Mater. Sci. Technol. 15, 127 (1999)

[31] L. Duprez, B.C. De Cooman, N. Akdut, Met. Mater. Trans. A 33, 1931 (2002)
[32] D. Samantaray, S. Mandal, C. Phaniraj, A.K. Bhaduri. Mater. Sci. Eng. A 528, 8565 (2011)

[33] H. Mirzadeh, J.M. Cabrera, A. Najafizadeh, Metall. Mater. Trans. A 43, 108 (2012)

[34] B.S. Xie, Q.W. Cai, W. Yu, L.X. Xu, Z. Ning, Acta Metall. Sin. (Engl. Lett.) 30(3), 250 (2017)

[35] Y.P. Li, R.B. Song, E.D. Wen, F.Q. Yang, Acta Metall. Sin. (Engl. Lett.) 29(5), 441 (2016)

[36] D.N. Zou, Z.Y. Chen, Y. Han, G.W. Fan, W. Zhang, Chin. J. Mater. Res. 25(6), 591 (2011)

[37] J.Q. Li, J. Liu, Z.S. Cui, Acta Metall. Sin. (Engl. Lett.) 28(11), 1364 (2015)

[38] A. Dehghan-Manshadi, M.R. Barnett, P.D. Hodgson, Mater. Sci. Technol. 23, 1478 (2007)

[39] C. Akihiko, L. Sang-Hak, M. Hiroaki, N. Mitsuru, Mater. Sci. Eng. A 513, 286 (2009)

[40] O. Balancin, W.A.M. Hoffmann, J.J. Jonas, Metal. Mater. Trans. A 31, $1353(2000)$

[41] L. Chen, X.C. Ma, X. Liu, L.M. Wang, Mater. Des. 32, 1292 (2011)

[42] Y.C. Zhu, W.D. Zeng, F. Feng, Y. Sun, Y.Y. Zhou, Mater. Sci. Eng. A 528, 1757 (2011) 